\title{
Visões de diretoras de escola sobre políticas públicas e determinações legais educacionais
}

\author{
Visions of school principals on public policies and educational legal \\ determinations \\ Visiones de directoras de escuela sobre políticas públicas y determinaciones \\ legales educativas
}

\section{CELSO LUIZ APARECIDO CONTI \\ EMÍLIA FREITAS DE LIMA \\ RENATA MARIA MOSCHEN NASCENTE}

\begin{abstract}
Resumo: Este trabalho analisa a visão de diretoras de escolas públicas de Ensino Fundamental do estado de São Paulo acerca de políticas públicas e determinações legais educacionais. Trata-se de pesquisa de natureza exploratória, com abordagem qualitativa, cujos dados foram obtidos por meio de questionário aplicado a 65 diretoras. Os resultados revelam visões positivas da quase totalidade das diretoras em relação às determinações legais eàs políticas educacionais estudadas, e uma gestão escolar baseada em lógica de controle em padrões hierarquizados mesclada com elementos do gerencialismo.
\end{abstract}

Palavras-chave: Políticas públicas educacionais; Gestão escolar; Autonomia da escola; Participação na escola.

Abstract: This work analyze the visions by principals of public schools of elementar education of the State of São Paulo about public policies and determinations of educational law. It deals with research of exploratory nature, withqualitative approach, whoose dataobtainedbyquestionnaireappliedto 65 principals. The resultsreveal positive visionsofalmostallofprincipals in relation to legal determinationsandeducational policies, and a school management basedonlogicofcontrol in hierarchicalstandardswithelementsofmanagerialism.

Keywords: Educational Policies; School Administration; School Autonomy; School Participation.

Resumen: Este trabajoanalizalavisión de directoras de escuelas públicas de Enseñanza Fundamental del estado de São Paulo acerca de políticas públicas y determinacioneslegales educativas. Se trata de investigación de naturalezaexploratoria, conabordajecualitativo, cuyosdatosfueronobtenidos por medio de uncuestionario aplicado a 65 directoras. Los resultados revelan visiones positivas de lacasitotalidad de lasdirectorasenrelación a lasdeterminacioneslegales ya las políticas educativas estudiadas, y una gestión escolar basadaen lógica de controlenpatronesjerárquicos combinados con elementos delgerencialismo.

Palabras clave: Políticas públicas educativas; Gestión escolar; Autonomia de laescuela; Participaciónenlaescuela. 


\section{INTRODUÇÃO}

O objetivo deste trabalho é analisar a visão de diretoras de escolas públicas de Ensino Fundamental do estado de São Paulo acerca de políticas públicas e determinações legais educacionais. Trata-se de pesquisa de natureza exploratória, com abordagem qualitativa (ALVES-MAZOTTI; GEWANDSZNAJDER, 1999), cujos dados foram obtidos por meio de questionário aplicado online, por mala direta, a 65 diretoras $^{1}$ que, em 2015, realizavam um curso de Especialização em Gestão Escolar na modalidade Educação a Distância, oferecido pela UFSCar em convênio com o MEC.

$\mathrm{Na}$ organização do questionário, optou-se por elaborar as questões e respectivos itens componentes, a partir do que estabelecem os documentos oficiais, preservando-se a fidelidade aos termos neles utilizados. A elaboração foi pautada em documentos como Brasil (1988); Brasil (1996); Brasil (2008). A fim de se preservar a identidade das respondentes, foi atribuído a cada questionário um código alfanumérico.

Neste texto é focalizada a visão das diretoras acerca da gestão democrática, com ênfase na participação e autonomia na construção do PPP; do PDDE; da avaliação externa; e do atendimento de alunos com necessidades educacionais especiais. Não foram analisados apenas os dados relativos à "Lei do Piso" e ao currículo, que completam as políticas e determinações legais abordadas pelo questionário.

O trabalho se organiza em quatro seções: a primeira traça um quadro de referência teórico; na segunda, são apresentados os resultados; na terceira, estes são problematizados à luz de três eixos de análise: participação; eficiência, eficácia, efetividade e relevância; qualidade da educação; na quarta, são tecidas as considerações finais.

\section{AS POLÍTICAS PÚBLICAS EDUCACINONAIS, AS DETERMINAÇÕES LEGAIS E A ESCOLA}

As políticas públicas e as determinações legais no campo educacional no Brasil devem ser vistas, por um lado, como resultado de um contexto de acordos internacionais, em função do processo de globalização, entendido como "revolução da tecnologia da informação" definida pela "transformação de nossa 'cultura material' pelos mecanismos de um paradigma tecnológico que se organiza em torno da tecnologia da informação" (CASTELLS, 1999, p. 67). Por outro

\footnotetext{
1 Referir-nos-emos às diretoras no feminino, dada a configuração de gênero dos profissionais atuantes no Ensino Fundamental no Brasil.
} 
lado, são também resultado do contexto nacional, marcado por dinâmica própria de caráter econômico, social, cultural e político, e de outros níveis ou esferas locais capazes de interferir no processo complexo de conformação e regulação ${ }^{2}$ da educação.

Nos anos de 1990, em consonância com as orientações dos organismos internacionais, o governo Fernando Henrique Cardoso (1995-2002) põe em curso a reforma do Estado, cujos pilares são bem definidos no Plano diretor da reforma do aparelho do Estado (BRASIL, 1995). A "grande tarefa política" seria superar seu suposto "gigantismo burocrático" e seus traços patrimonialistas e clientelistas. Esse Estado seria combatido com nova racionalidade administrativa, de caráter gerencialista, capaz de promover a administração pública moderna, voltada

\begin{abstract}
(1) Para a definição precisa dos objetivos que o administrador público deverá atingir em sua unidade, (2) para a garantia de autonomia do administrador na gestão dos recursos humanos, materiais e financeiros que lhe forem colocados à disposição para que possa atingir os objetivos contratados, e (3) para o controle ou cobrança $a$ posteriori dos resultados (p. 16).
\end{abstract}

Pretendia-se, portanto, enfraquecer o papel de 'executor' do Estado e reforçar suas funções de 'regulador', 'provedor', 'promotor' dos serviços públicos, assegurando sua qualidade via 'controle social direto', pela 'participação da sociedade'. Isso exigiria a 'descentralização vertical' na execução dos serviços públicos, envolvendo mais os níveis estadual e municipal (BRASIL, 1995).

Nos anos 2000, o governo Luiz Inácio Lula da Silva (2003-2010) coloca ênfase diferente em relação à visão do papel do Estado e, por conseguinte, das políticas públicas. Seu plano de governo, de perspectiva 'neodesenvolvimentistista', preconiza um 'novo contrato social', um 'novo pacto federativo', contrapondo-se, em parte, ao neoliberalismo, por estabelecer "uma nova lógica na formulação e condução das políticas sociais.” (FREITAS; SILVA, 2016, p. 70-71) Como nem tudo foi tão radicalmente novo, em termos de tendências nas políticas públicas educacionais, é possível se falar em continuidades e rupturas (OLIVEIRA, 2009, p. 207). Sobre a gestão da Educação Básica em particular, há, no governo Fernando Henrique Cardoso "um entendimento de democratização da gestão educacional quase como sinônimo de racionalidade técnica e eficácia econômica”, enquanto no governo Lula predomina “a intenção de distribuição do poder segundo os pressupostos de um projeto político-participativo” (AZEVEDO, 2009, p. 228).

\footnotetext{
2 Tomamos aqui o conceito de Barroso (2006), para quem a regulação serve "para descrever dois tipos de fenômeno diferenciados, mas interdependentes: os modos como são produzidas e aplicadas as regras que orientam a ação dos actores; os modos como esses mesmos atores se apropriam delas e as transformam” (p. 13).
} 
Um dos alvos principais das políticas foi, em ambos os governos, a escola, que tem assumido importância cada vez maior em termos de resultados educacionais, seguindo tendência internacional. Nóvoa (1999, p. 22-23), por exemplo, ao se referir à trajetória dos estudos sobre escolas eficazes", descreve suas fases, das quais se destacam as duas últimas (anos 1980-1990): fase da 'contextualização', quando a escola é chamada a cumprir um papel de liderança nas redes de relações com seu entorno social; fase da "excelência", marcada pelas ideias de mercado, na perspectiva do gerencialismo (BALL, 2005, BRASIL, 1995). Assim, a escola assume certo protagonismo, vista como "territorialidade espacial e cultural", não unidade de gestão meramente técnica (NÓVOA, 1999, p. 16); como "lócus de reprodução e lócus de produção de políticas, orientações e regras" (LIMA, 2003, p. 93-95).

Esse movimento de crescente reconhecimento da importância do papel social da escola traz consigo, ao mesmo tempo, sua responsabilização, às vezes exagerada. Nesse sentido, Barroso (2003) fala da mudança da "lógica da reforma" para a "tirania da transformação" (Clarke; Newman, 1997 apud BARROSO, 2003, p. 117), que exige da escola adaptação contínua, podendo retirar dela sua dinâmica inovadora, criativa e crítica. O excesso de regras é substituído pelo excesso de demandas, e sua ação autônoma se esvai, restringindo-se ou se reconfigurando a participação, que se torna bem menos politicamente ativa. Os vazios institucionais, inalcançados pelas regras formais e com potencial transformador, convertem-se em espaços de risco, porque não há mais clareza de orientação das ações. Sennett (1999), a propósito, alerta para o perigo da "flexibilidade", capaz de desorganizar a vida das organizações e das pessoas e de quebrar identidades individuais e coletivas.

As determinações legais e as políticas educacionais podem e devem orientar as escolas, tornando-as instituições mais vigorosas, no que tange ao cumprimento do seu papel social; mas elas podem, também, produzir mais instabilidade, confundindo as escolas no plano da sua percepção e ação educativas. O desafio é indicar a ela o caminho a percorrer em busca de uma atualização que lhe garanta um senso de responsabilidade social e, ao mesmo tempo, um sentido coletivo que a justifique como instituição, o que vale também para as pessoas que dela fazem parte. Cabe à escola a difícil tarefa de se auto-organizar em meio ao ruído, sem perder de vista a "aposta categórica na potência reformadora da 'sociedade civil' [que se converteu] num dos mais decisivos campos políticos e intelectuais da modernidade" (NOGUEIRA, 2011, p. 86). O gestor escolar, diante desse quadro, 
Precisa agir como educador, como político, como alguém que produz sentido para os demais e que promove a constante aproximação entre as pessoas e a organização: um intelectual, mais que um especialista, para usar uma famosa conceituação de Antônio Gramsci (Idem, p. 212-3).

É a partir desse quadro de referência que os dados empíricos encontrados na pesquisa são analisados. Buscam-se indícios de como as políticas e as determinações legais educacionais chegam às escolas e de como seus efeitos são percebidos por suas diretoras.

\section{GESTÃO DEMOCRÁTICA: PARTICIPAÇÃO E AUTONOMIA}

Neste trabalho, foram tomados como indicadores de participação a forma de elaboração e de acompanhamento do PPP, além da articulação da escola com as famílias e articulação da escola com a comunidade de entorno.

As respostas indicam que $97 \%$ das escolas têm PPP e que participam de sua elaboração, predominantemente, as diretoras (94\%); as coordenadoras pedagógicas $(89 \%)$ e as/os professoras/es (76\%). Por outro lado, apenas $17 \%$ das famílias participariam da elaboração do PPP. Já quanto a sua atualização, 94\% das diretoras informam que ele é atualizado periodicamente.

Quanto à articulação da escola com as famílias (BRASIL, 1996), $100 \%$ das respondentes apontam que ela existe, sendo que a minoria aponta que ocorre com muita intensidade (8\%); a maioria com intensidade (71\%); e 21\% com pouca intensidade.

Perguntadas sobre como a articulação da escola com as famílias interfere na atuação da diretora, destacam-se as justificativas relacionadas a aspectos pedagógicos, visando à aprendizagem dos alunos. Com menor intensidade, também aparecem a possibilidade de troca de experiências; "a desmistificação da autoridade incontestável e centralizadora [da diretora]" (D24); a ajuda na gestão de conflitos e na articulação com segmentos como Conselho Escolar e APM.

No que se refere à articulação da escola com a comunidade de entorno (BRASIL, 1996), verificam-se indicadores próximos aos anteriores, a saber: $62 \%$ das diretoras a consideram intensa; $26 \%$ pouco intensa e $7,5 \%$ muito intensa. Diverge apenas o fato de 3\% indicarem ausência de articulação com o entorno e de uma diretora não ter respondido.

Diferentemente da relação com as famílias, na qual se destacou a preocupação pedagógica, aqui prevalece a alusão à parte física da escola: manutenção predial e patrimonial; realização de eventos e festas. São feitas alusões também, com menor intensidade, à resolução de conflitos; à sensação de conforto e de respaldo na tomada de decisões; à rapidez nas ações. 
Já quanto à demanda da comunidade em relação à escola, destaca-se o uso das dependências desta por entidades como igrejas, associações, ex-alunos etc., como forma de suprir a ausência de espaços comunitários (praças, centros, locais de lazer).

Como contraponto aos aspectos positivos da participação da comunidade de entorno, há alusão às dificuldades dela decorrentes, mormente quanto à sobrecarga de trabalho, dando indícios de que a participação seria vista como acréscimo às funções próprias da diretora e considerada como algo secundário.

As diretoras foram também instadas a citar dimensões nas quais teriam muita autonomia, tendo indicado as seguintes: elaboração do PPP (82\%), manutenção da disciplina (75,5\%), desempenho escolar dos alunos (71\%). Com menor intensidade, aparecem a gestão administrativa $(57,5 \%)$, a gestão financeira $(50 \%)$ e as definições de caráter didático $(48,5)$, dimensões nas quais se verifica grande dispersão nas respostas. Já com relação à manutenção do espaço físico e definições curriculares, predominam as respostas referentes a uma razoável autonomia ( $42 \%$ e $41 \%$ respectivamente). Ademais, na dimensão de ampliação do espaço físico, há indicação de pouca ou nenhuma autonomia (77\%).

Retomando-se a participação e autonomia como elementos fundamentais da gestão democrática, nota-se que a determinação feita pela LDBN (BRASIL, 1996) sobre a obrigatoriedade do PPP parece estar incorporada à cultura das escolas, tanto que, além de ele ser elaborado, é periodicamente atualizado. Ainda sobre a participação, os dados fornecem indícios de que a relação escola-família teria um sentido de "mão única": trazer as famílias e a comunidade de entorno à escola para melhor qualificar suas demandas e fazer com que se tornem corresponsáveis na tomada de decisões e no aumento da eficiência do trabalho escolar. No entanto, apesar de ser considerada bastante positiva na visão das diretoras, a participação das famílias e da comunidade representaria um plus em relação às suas funções supostamente essenciais.

Finalizando esta seção, os resultados não apontam para a autonomia construída - já que esta implica a existência de objetivos próprios da unidade escolar, elaborados coletivamente - mas para um centralismo de poder, principalmente nas mãos da diretora. Isso ocorre, entre outras coisas, em função das demandas às quais ela tem de atender, nos limites estreitos dos recursos que lhe são disponibilizados - como é o caso dos recursos financeiros, gastos majoritariamente na infraestrutura pedagógica - ou seja, nos limites próprios da autonomia decretada. 


\section{PROGRAMA DINHEIRO DIRETO NA ESCOLA (PDDE)}

Com relação aos efeitos do PDDE sobre a escola, o conjunto de respostas válidas revela as seguintes visões das diretoras: $87 \%$ indicam efeito positivo; $2 \%$ negativo e $11 \%$ entendem que o PDDE não produz efeito na escola.

Os efeitos positivos incidem sobre a infraestrutura pedagógica, segundo a indicação unânime das diretoras. Nesse caso, o grande destaque foi para a aquisição de materiais pedagógicos (livros, brinquedos, jogos, materiais escolares) e equipamentos (computador, impressora, rádio, data show). Um dado interessante é a possibilidade de liberdade e autonomia na aquisição de tais materiais.

Quanto aos demais itens, temos a seguinte situação:

Infraestrutura física - manutenção do prédio (elétrica, hidráulica e pintura) e, com menos ênfase, dos equipamentos;

Autogestão escolar no plano financeiro - ênfase na liberdade de efetuar aquisições mais condizentes com a realidade da escola: "A escola pode, com esta pequena verba, decidir o que fará com o dinheiro, e essas necessidades conversam mais com a realidade da escola. [...] Com o dinheiro do PDDE podemos refletir melhor sobre os rumos do dinheiro". (D18)

Autogestão escolar no plano administrativo - possibilidade de maior envolvimento da comunidade escolar em função de mais autonomia/liberdade do uso dos recursos financeiros: "As decisões do gasto da verba do PDDE dependem do Conselho de Escola, e isso facilita o trabalho e a autogestão da execução do plano administrativo." (D49); "Permite diagnosticar as necessidades e traçar plano de ação, priorizando-se os itens mais relevantes.” (D50).

Autogestão escolar no plano didático - reitera-se a ideia de autonomia e liberdade: "Aquisição de recursos didáticos que auxiliem no processo ensinoaprendizagem." (D38); "Didaticamente, podemos atender às necessidades dos professores e alunos." (D42).

Das respostas negativas (2\%), sobressai a indicação de insuficiência dos recursos e consequente não atendimento de todas as necessidades.

Indagadas sobre a relação entre elevação dos índices de desempenho escolar e aplicação dos recursos do PDDE, a maioria respondeu afirmativamente (74\%). A análise das justificativas apresentadas denota respostas genéricas, sem apoio em dados objetivos que correlacionem ambos os aspectos. Isso pode ser observado em respostas como as seguintes: 
Os professores registram o aumento de interesses dos alunos quanto às aulas, devido às mesmas serem mais práticas, pois são utilizados os materiais concretos e tecnológicos adquiridos com a verba do PDDE (D4);

Aquisição de jogos, materiais pedagógicos, materiais de educação física têm melhorado a concentração [dos estudantes], transformando a escola num lugar de aprender com alegria (D5).

As referidas análises podem ser indícios de ausência de estudos mais sistemáticos acerca dos efeitos dos programas governamentais, tanto na atividade gestora das escolas, quanto na das administrações centrais nos diversos âmbitos, haja vista a inconsistência na correlação entre os aspectos mencionados pelas diretoras. Exemplo: a disponibilidade do recurso permite a aquisição de materiais didáticos que tornariam as aulas mais "práticas", "alegres", resultando, assim, em melhora na "concentração" e em uma aprendizagem "com alegria".

Pode-se, ainda, observar que as diretoras têm uma visão bastante positiva sobre os efeitos do PDDE na escola, principalmente porque ele favoreceria maior grau de autonomia e liberdade no uso de recursos para possibilitar aquisições mais condizentes com a realidade da escola, destacando-se a ênfase atribuída por elas à infraestrutura pedagógica.

A partir dos dados sobre o PDDE, destacamos dois aspectos: valorização dos efeitos positivos dessa política versus dificuldade de reconhecer seus pontos negativos; concepção de autonomia e liberdade subjacentes a tal política.

\section{AVALIAÇÕES EXTERNAS}

Das participantes, $62 \%$ consideraram que as avaliações externas interferem diretamente em seu trabalho; 29\% responderam que não há essa interferência; 9\% não responderam a essa questão. Das diretoras que afirmaram haver interferência das avaliações externas em seu trabalho, 93\% consideraram essa interferência como positiva e apenas 7\% consideraram-na negativa, não tendo explicado as razões dessa visão.

O lado positivo dessas avaliações, para as diretoras, refere-se principalmente a incentivos para que a equipe gestora, professores, estudantes e pais se empenhem em melhorar a qualidade do ensino e da aprendizagem, como revela, por exemplo, a seguinte fala de P57: [a avaliação externa] "Faz com que a equipe se mantenha focada na qualidade de ensino”. A concepção de qualidade corresponderia àquela proposta pela política de avaliação, tendo por base os índices oficiais dela decorrentes. Isto é, o que as avaliações pretenderiam medir se foi aprendido ou não seria justamente o que os alunos precisariam aprender, de modo que as avaliações externas trabalhariam a favor das aprendizagens que 
realmente importam. A fala de P30, por exemplo, indica isso literalmente: as avaliações externas "Me fazem interagir melhor com o currículo e a real prática em sala de aula. E assim posso trabalhar a favor dos índices".

Como se vê, o currículo é outra dimensão trazida nas justificativas das que consideram positivos os efeitos das avaliações externas, como indicam também as falas de P31 e P54 respectivamente: “Contribuem para reorganização do currículo; Podemos adaptar o currículo, o planejamento, nos direcionando para as dificuldades apresentadas a fim de saná-las. "Dessa forma, pode-se entender que as avaliações externas definem os rumos do trabalho na escola. Além disso, os índices interferem diretamente no estímulo para que a escola cumpra as metas, como justifica P32, por exemplo: "Mais estímulo para cumprir as metas propostas."

Além disso, para algumas diretoras, as avaliações externas estimulariam investimentos em recursos pedagógicos; facilitariam o planejamento escolar com base nos indicadores produzidos por elas; e auxiliariam na compreensão de problemas relativos à evasão escolar e repetência. Elas também indicaram que, quando a escola atinge as metas estabelecidas pelas avaliações, a tendência das equipes e dos estudantes é o aprimoramento constante, isto é, ao se sentirem recompensados pelos resultados das avaliações, os diferentes atores escolares ficariam mais motivados para continuar avançando.

Esses dados demonstram a incorporação das avaliações externas aos discursos e práticas das diretoras. Dessa forma, essas avaliações assumem função regulatória, sendo consideradas pelas diretoras como componente imprescindível e indispensável da organização e funcionamento da escola.

\section{ATENDIMENTO DE ALUNOS COM NECESSIDADES EDUCACIONAIS ESPECIAIS}

Com relação a este tema foram considerados os dispositivos previstos na LDBN (BRASIL, 1996) para a formulação das questões.

Interrogadas sobre se o sistema de ensino ao qual a escola está vinculada oferece serviços de apoio especializado aos estudantes com necessidades educacionais especiais, 75\% responderam que $\operatorname{sim}, 20 \%$ que não, e $5 \%$ deixaram em branco.

Em seguida, as diretoras foram instadas a responder sobre o efeito desses serviços de apoio especializado sobre o seu trabalho. Das 49 que responderam que a escola possui alguns desses serviços, o efeito foi avaliado: $56 \%$ como muito positivo; $33 \%$ como positivo; $4 \%$ responderam muito negativo ou que não tem efeito; $7 \%$ deixaram em branco. 
O Art. 59 da LDBN (BRASIL, 1996) determina que os sistemas de ensino assegurarão aos educandos com necessidades especiais algumas condições diferenciadas. Diante disso, as diretoras deveriam indicar o grau de satisfação com que algumas condições são asseguradas na sua unidade escolar. Consideradas em conjunto as alternativas "muito satisfatório" e "satisfatório" X "pouco satisfatório" e "nada satisfatório", as respostas demonstram que as condições vistas como mais satisfatoriamente asseguradas são, pela ordem: "Métodos, técnicas, recursos educativos" (75\%), “Organização escolar específica” (71\%), "Professores com especialização adequada em nível médio ou superior, para atendimento especializado" (69\%) e "Currículos" (61\%). No outro extremo, destaca-se a condição "Professores do ensino regular capacitados para a integração desses educandos nas classes comuns", com 54\% de "pouco satisfatório" e "nada satisfatório".

Reitera-se a constatação da visão positiva das diretoras sobre os efeitos das determinações legais e das políticas educacionais, apesar do destaque relativo ao fato de que os professores regulares não estão devidamente capacitados para lidar com alunos com necessidades educacionais especiais, o que dificulta sobremaneira o processo de inclusão.

\section{DISCUSSÃO DOS RESULTADOS}

Os resultados obtidos neste trabalho serão discutidos a partir de três eixos analíticos: participação; eficácia, efetividade e relevância; e qualidade da educação. Busca-se analisar os efeitos das políticas públicas e das determinações legais educacionais aqui consideradas sobre a escola, na visão das diretoras, no que se refere aos referidos eixos.

\section{PARTICIPAÇÃO}

Há a incorporação de uma determinada forma de gestão, por parte das escolas, com forte presença de elementos característicos do gerencialismo, entendido como nova forma de poder que orienta a reforma da estrutura e da cultura dos serviços públicos (BALL, 2005).

A participação se revela, para as diretoras, como uma espécie de "recurso gerencial", pois ela: 
Tende a converter-se em um instrumento para solidarizar governantes e governados, para aliviar e agilizar a ação governamental, para compartilhar custos e decisões, para reduzir atritos entre governos e sociedade. Participar passa a significar também uma forma de interferir, colaborar, administrar. (NOGUEIRA, 2011, p. 144-5).

Essa forma de participação se observa, em alguma medida, na relação da escola com as famílias e com a comunidade de entorno, como se viu. Ambas são vistas pelas diretoras como meios de explicitar melhor as demandas em relação à escola e para ajudá-la a atendê-las, configurando-se, assim, como uma relação de mão única, característica de um modelo de tipo clientelista. A diretora, premida pela necessidade de compreender e satisfazer demandas das mais variadas, vêse numa posição defensiva, buscando sempre uma zona de conforto frente à realidade cambiante, insegura e instável. Nos dados, essa ideia aparece associada ao "respaldo na tomada de decisões".

O tema da participação implica diretamente o da autonomia: autonomia decretada e autonomia construida (BARROSO, 1996). A primeira definição exprime o conjunto de normas estabelecido por órgãos superiores, responsáveis pela administração da educação, que define as margens de liberdade de ação das unidades escolares. A segunda refere-se às formas autônomas de tomada de decisão desenvolvidas pelas escolas em diferentes domínios, por meio de ação organizada e em função de objetivos coletivos próprios.

Para Levacic (apud BARROSO, 1996) há diferentes configurações possíveis de autonomia das escolas, relacionadas com o contexto em que ela se desenvolve. Tais configurações se definem em função de três elementos-chave: os órgãos de decisão para os quais o poder será descentralizado (diretores, professores, pais, comunidade local, setor econômico); os domínios de gestão em que o poder será exercido (orçamento, recursos físicos, professores, currículo, seleção dos alunos); e as formas de regulação pelas quais se dará o controle (usos de recursos, especificação de produtos, condições de mercado).

Com relação aos órgãos de decisão sobre os quais recai a descentralização, pode-se observar que as diretoras aparecem como figura central em termos de acumulação de poder. Isso não significa que não haja participação de outros atores. Assim, por exemplo, 100\% das diretoras responderam que existe relação intensa ou muito intensa da escola com as famílias (79\%). Só que, correlacionando esse dado com o dos setores que participam da elaboração do PPP, vemos que apenas $17 \%$ das diretoras indicam a existência dessa participação. Por outro lado, se for considerada a participação de outros segmentos, fica evidente a correlação entre grau de participação e níveis hierárquicos na escola. Dessa forma, observam-se 
nitidamente dois extremos: o que envolve diretoras, coordenadoras pedagógicas e professoras; e o que congrega os funcionários (não docentes), os alunos, as famílias e a comunidade de entorno, nessa ordem.

A participação desses últimos segmentos é vista pelas diretoras como um recurso necessário para que suas funções, nos limites do que lhes é outorgado pelas regras formais, sejam desempenhadas de forma mais eficiente e eficaz, porém de modo a não ameaçar seu poder. Assim, não se verifica descentralização de poder no âmbito da escola, mas concentração dele principalmente na mão da diretora. Talvez isso se deva à indução dos novos modelos de gestão que preconizam o controle do produto mais do que do processo, jogando nos ombros da autoridade máxima da escola a responsabilidade de alcançar metas e objetivos estabelecidos pelas instâncias superiores da administração da educação.

Quanto aos domínios de gestão, prevalece o referente ao uso de recursos financeiros, especificamente os advindos do PDDE. Eles são utilizados, majoritariamente, na infraestrutura pedagógica, em especial para a aquisição de materiais pedagógicos e equipamentos, o que, na visão das diretoras, incidiria positivamente sobre o desempenho escolar dos alunos. Já a infraestrutura física, financeira e administrativa aparecem nos dados como envolvendo menor autonomia.

Fica reiterada a priorização de aspectos pedagógicos sobre os demais (físico, financeiro e administrativo), o que tem a ver com o fato de os recursos serem escassos e, portanto, insuficientes para atender a todos os âmbitos da gestão.

Sobre as formas de regulação, elas se fazem sentir mais nitidamente no que se refere aos efeitos das avaliações externas. Da forma como são consideradas pelas políticas públicas, elas acabam por promover a inversão de prioridades com relação ao currículo e ao planejamento, que se veem reféns dos índices resultantes das avaliações. Assim, em vez de as avaliações servirem como subsídio para se (re)pensar o currículo e o planejamento, estes são configurados com base nos resultados das avaliações. Mesmo assim, as respostas das diretoras revelam que elas consideram positiva a existência das avaliações externas.

Do que se vê nos resultados, não se poderia falar em autonomia construída, já que esta implica a existência de objetivos próprios da unidade escolar, construídos coletivamente. Como se disse, há um centralismo de poder, principalmente nas mãos da diretora, em função das demandas que ela tem de atender, nos limites estreitos dos recursos que lhe são disponibilizados - como é o caso dos recursos financeiros, gastos majoritariamente na infraestrutura pedagógica - ou seja, nos limites próprios da autonomia decretada. 


\section{EFICÁCIA, EFETIVIDADE E RELEVÂNCIA}

Nota-se, com base no material empírico, certa tendência a uma gestão de tipo gerencialista, em que predomina a eficácia em detrimento da efetividade e da relevância. Estes conceitos são assim definidos por Sander:

\footnotetext{
eficiência - critério econômico que traduz a capacidade administrativa de produzir o máximo de resultados como mínimo de recursos, energia e tempo; eficácia - é o critério institucional que revela a capacidade administrativa para alcançar metas estabelecidas ou resultados propostos; efetividade - critério político que reflete a capacidade administrativa para satisfazer as demandas concretas feitas pela comunidade (...) refletindo a capacidade de resposta às exigências da sociedade; relevância - critério cultural que mede o desempenho administrativo em termos de importância, significação, pertinência e valor (...) guarda relação com as consequências de sua atuação para a melhoria do desenvolvimento humano e da qualidade de vida na escola e na sociedade (SANDER, 2007, p.75-83).
}

Os dados da pesquisa não permitem analisar o conceito de eficiência, razão pela qual serão abordados apenas os outros três.

No que se refere ao PPP, há evidências de elevada participação da equipe gestora e das professoras na sua elaboração, além de intensa articulação da escola com as famílias e com a comunidade de entorno. Do ponto de vista da eficácia, pode-se dizer que as diretoras se movimentam em busca da mobilização das pessoas, em função da compreensão delas sobre gestão democrática, que envolve um caráter instrumental, vista como "recurso gerencial". Por conta disso não se poderia falar em efetividade e relevância, porque a participação se volta, por exemplo, para aspectos físicos da escola e para a cessão de suas dependências ao uso da comunidade. Assim, elementos centrais, como construção do PPP, definição curricular e participação nos processos deliberativos da escola não ocorrem, comprometendo a participação e a autonomia efetivas.

Os resultados referentes ao PPDE, por sua vez, evidenciam relação mais direta com o conceito de eficácia. As diretoras dizem conseguir o máximo de resultados com os parcos recursos oriundos do governo federal. Incrementar a infraestrutura pedagógica, principalmente com materiais e equipamentos, incidiria positivamente sobre o desempenho escola dos alunos. Segundo as diretoras, o ponto alto desse programa é a liberdade e autonomia nas aquisições que ele proporciona.

Da mesma forma que o PDDE, os resultados concernentes às avaliações externas e às necessidades educacionais especiais poderiam ser relacionados à eficácia. Quanto às primeiras, a mobilização da escola e as ações por ela encaminhadas produzem, na visão das diretoras, resultados positivos de 
desempenho escolar em termos das metas estabelecidas, gerando índices mais altos de rendimento escolar dos alunos. Sobre as necessidades educacionais especiais, os resultados positivos de desempenho escolar são percebidos em função de métodos, técnicas, recursos educativos; organização escolar específica; professores com especialização adequada em nível médio ou superior, para atendimento especializado; e currículos.

\section{QUALIDADE DA EDUCAÇÃO}

A educação é uma prática social desenvolvida nas instituições educativas - seu locus privilegiado - e tem como compromisso fundamental a garantia de direitos. Assim concebida, ela pressupõe uma qualidade sempre situada historicamente, baseada no sistema de valores de determinado projeto social, capaz de orientar a construção de determinada política nacional de educação. A qualidade da educação, portanto, deve ser sempre referenciada socialmente e voltada para a formação do cidadão, com vistas à manutenção e à transformação da realidade.

O tema da qualidade da educação vem ganhando espaço no debate educacional, produzindo alguns avanços no plano das leis e das ações de governos no país, ainda que a efetivação de uma escola de qualidade se tenha mostrado como algo bastante complexo e desafiador. Desse modo, ao mesmo tempo em que se adotou, no Brasil, determinada "lógica político-pedagógica voltada para a ampliação das oportunidades educacionais, não se avançou em termos da definição de qualidade pretendida”. (Dourado e Oliveira, 2009, p. 202 e 204)

O PNE, (BRASIL, 2014), acompanhando a CF/88 (BRASIL, 1988) e a LDBN (BRASIL, 1996) - que asseguram "garantia de padrão de qualidade" estabelece, no Art. 11, que o Sistema Nacional de Avaliação da Educação Básica "constituirá fonte de informação para a avaliação da qualidade da educação básica e para a orientação das políticas públicas desse nível de ensino”.

Desse modo, a política nacional relativa à qualidade da educação, nos termos propostos pelo PNE (BRASIL, 2014), define os parâmetros dessa qualidade, por meio do reconhecimento da necessidade de se contemplarem diferentes dimensões, em consonância com o previsto no inciso IX da LDBN (BRASIL, 1996), que se refere à "variedade e quantidade mínimas, por aluno, de insumos indispensáveis ao desenvolvimento do processo de ensinoaprendizagem". Essas dimensões envolvem: incremento de recursos públicos para a educação, consideração de aspectos intraescolares e extraescolares, avaliação específica para os níveis e modalidades de ensino, estabelecimento de prazos para se implementarem algumas medidas, etc. Destaque especial cabe à adoção 
do Custo Aluno Qualidade - CAQ - como parâmetro para o financiamento da educação de todas etapas e modalidades da educação básica e do Índice de Desenvolvimento da Educação Básica - IDEB - cujas médias nacionais propostas servem para fomentar a qualidade da educação básica.

Pouco se avançou ainda na implementação do CAQ, ao contrário da utilização do IDEB, que tem assumido papel fundamental na definição de qualidade do ensino. Abdian e Oliveira (2015) destacam que, notadamente por meio das diversas mídias, tem-se enfatizado a ligação intrínseca entre resultados obtidos pelas escolas nas avaliações externas e determinada concepção de qualidade da educação, vinculada a um ideário neoliberal que a significa como capacidade das escolas de preparem estudantes das camadas populares para atender às necessidades do mercado de trabalho. Então, o baixo rendimento de estudantes em testes que normalmente medem conhecimentos nas áreas de Língua Portuguesa e Matemática seria indicador de deficiências que comprometeriam o desempenho dos futuros trabalhadores.

É possível verificar, nos resultados da pesquisa, alguns parâmetros ou critérios utilizados para se definir a qualidade da educação. A boa participação da equipe gestora e das professoras na elaboração do PPP; a intensa articulação da escola com as famílias e com a comunidade de entorno; a autonomia para se elaborar o PPP, para se manter a disciplina dos alunos e para atuar na melhoria do seu desempenho escolar; tudo isso interfere indiretamente na qualidade da educação, segundo as diretoras.

O mesmo se daria com o PDDE. Embora os recursos dele oriundos sejam insuficientes, eles são manejados com mais liberdade, permitindo incremento dos recursos pedagógicos e aquisição de materiais e equipamentos, o que melhoraria o processo de ensino-aprendizagem e os índices de desempenho escolar dos alunos.

Bem mais influente que os aspectos anteriores na qualidade da avaliação é, à luz dos resultados da pesquisa, a avaliação externa. Como já assinalado, ela induz fortemente o currículo e o planejamento da unidade escolar, permitindo supostamente a elevação dos índices de desempenho dos alunos. Isso sinaliza para uma concepção de educação vinculada a um sistema de valores, a um projeto social que lhe dá sentido bastante limitado, a nosso ver. E isso corresponde ao art. 11 do PNE (BRASIL, 2014), que coloca o Sistema Nacional de Avaliação como fonte de informação para a avaliação da qualidade da Educação Básica e para a orientação das políticas públicas, como assinalado.

Quanto às necessidades educacionais especiais, os dados da pesquisa mostram a presença de condições favoráveis para seu atendimento nas escolas. 
Nesse sentido, apropriados métodos, técnicas, recursos, organização curricular e especialização dos professores estariam favorecendo a qualidade de ensino dos alunos com necessidades especiais.

\section{CONSIDERAÇÕES FINAIS}

Este trabalho procurou compreender as visões de um grupo de diretoras sobre as políticas públicas e as determinações legais. A tematização dos dados evidenciou que, no discurso das diretoras, as políticas e as determinações legais aqui analisadas são vistas por elas de maneira bastante positiva, por alguns motivos principais. Primeiro, porque estariam suprindo melhor a escola com os recursos necessários face às suas demandas. Segundo, porque permitiriam maior autonomia e liberdade de gestão, revertendo em melhoria de alguns resultados. O terceiro motivo teria a ver com o fato de elas estabelecerem, no mínimo, alguns parâmetros para a ação educativa da escola - as políticas e as determinações legais prescrevem o que tem que ser feito e como fazer.

De forma diferente e em graus variados, essa visão bastante positiva das diretoras está presente nos três eixos analíticos utilizados.

No primeiro eixo, relativo à participação, nota-se que esta se apresenta mais acentuadamente como um "recurso gerencial", um plus na escola, ao invés de ser um elemento fulcral na efetivação da gestão mais democrática. Desse modo, ela não induz a mudanças substantivas no modo de gerir a escola, ainda assentada na lógica de controle em padrões hierarquizados.

Sobre o segundo eixo analítico - eficácia, efetividade e relevância - é patente a preocupação muito mais forte com a eficácia, em detrimento da efetividade e da relevância. Isso se vê nos dados relativos à participação, ao PPDE, às avaliações externas e às necessidades educacionais especiais. No primeiro caso, a participação está voltada apenas para a melhoria de aspectos físicos da escola e para o uso do mesmo pela comunidade de entorno. No segundo, prevalece a capacidade administrativa de produzir o máximo de resultados com os parcos recursos que chegam à escola. No caso da avaliação externa, a escola se empenha em melhorar seus índices de desempenho dos alunos. Por fim, esse mesmo efeito, agora sobre os alunos com necessidades especiais, produziria a estrutura e o funcionamento adequados dos serviços especializados.

No terceiro eixo de análise, da qualidade da educação, a maior eficácia na ação da escola se revelaria na melhoria da disciplina, com consequências positivas sobre o processo de ensino-aprendizagem e sobre os índices de desempenho escolar dos alunos. Os fatores responsáveis por isso seriam: participação de professores na construção do PPP e articulação da escola com a comunidade; 
incremento dos recursos pedagógicos e aquisição de materiais e equipamentos, por conta do PDDE; avaliação externa, porque ela induz fortemente o currículo e o planejamento da unidade escolar; recursos apropriados para o atendimento dos alunos com necessidades especiais (currículo, métodos e técnicas utilizados e profissionais capacitados).

Depreende-se do conjunto dos dados que o modelo burocrático de administração das escolas ainda continua forte. Figurativamente, as relações entre sistema, escola e comunidade poderiam ser apresentadas como concêntricas, de modo que a segunda se coloca a serviço da primeira e a terceira a serviço da segunda, em interações mais marcadas pela heteronomia do que pela autonomia.

Mas esse modelo aparece mesclado com elementos típicos do gerencialismo. Mais eficaz, nos termos das políticas públicas e das determinações legais, a escola se vê melhor direcionada - ou teleguiada - em alguma medida, perdendo, assim, efetividade e relevância em sua ação administrativa. Forçada à adaptação contínua, ela compromete a capacidade de se vincular a um projeto social referenciado socialmente, perdendo sua vitalidade democrática, sua autonomia e sua capacidade de transformação.

Embora tenha havido referências a maior eficácia nas ações da escola , convém ressaltar a presença de muitas ilações no discurso das diretoras. Nem sempre as correlações feitas entre alguns fatores decorrentes das políticas públicas e das determinações legais e os resultados obtidos pela escola ficam bem evidenciados. Isso, no entanto, parece não ser percebido pelas diretoras, haja vista, por exemplo, o caso do PDDE, em que a verba é diminuta e, mesmo assim, o programa é supervalorizado por elas em função de suposta liberdade e autonomia que ele proporcionaria.

Ao mesmo tempo que foi possível compreender as razões que as próprias diretoras atribuem à sua visão positiva acerca das políticas públicas e determinações legais, esta pesquisa propõe outra questão, a ser melhor investigada: Por que essa percepção tão positiva das diretoras, mesmo sem lastro em dados objetivos? A relevância dessa indagação tem a ver com o fato de que, mesmo considerando a forte influência das diretrizes internacionais, dos sistemas, é importante levar em conta o papel das escolas e dos seus atores no processo complexo de regulação da educação, incluindo a visão das diretoras escolares, foco deste estudo. 


\section{REFERÊNCIAS}

ABDIAN, G. Z; OLIVEIRA, M. E. N. Gestão e qualidade da educação de escolas estaduais paulistas no contexto dos indicadores de desempenho. Revista Brasileira de Política e Administração da Educação. Recife: ANPAE, v.31, n. 1; p.177-195, jan./abr. 2015.

ALVES-MAZZOTTTI, J.; GEWANDSZNAJDER, F. O método nas ciências naturais e sociais: pesquisa quantitativa e qualitativa. $2^{\mathrm{a}}$ ed. São Paulo: Pioneira, 1999.

AZEVEDO, J. M. L. Programas federais para a gestão da educação básica: continuidade e mudanças. Revista brasileira de política e administração da educação. Porto Alegre, v. 25, n. 2, p. 211-231, maio/ago. 2009.

BALL, S. J. Profissionalismo, gerencialismo e performatividade. Cadernos de Pesquisa, v. 35, n. 126, p. 539-564, set./dez. 2005.

BARROSO, J. A investigação sobre a regulação das políticas públicas de educação em Portugal. In: BARROSO, J. (Org.). A regulação das políticas públicas de educação: espaços, dinâmicas e atores. Lisboa: Educa, 2006. p. 9-39.

A formação dos professores e a mudança organizacional das escolas. In: FERREIRA, N. S. C. (Org.). Formação continuada e gestão da educação. São Paulo: Cortez, 2003. p. 117-143.

O estudo da autonomia da escola: da autonomia decretada à autonomia construída. In BARROSO, J.O estudo da Escola. Porto: Porto Ed., 1996.

BRASIL. Lei no 13005, de 25 de junho de 2014. Aprova o Plano Nacional de Educação e dá outras providências, 2014. Diário Oficial da União, Brasília, DF, 2014. Disponível em: < http://www.planalto.gov.br/CCIVIL_03> Acesso: 4mar. 2017.

Ministério da Educação. Conselho Nacional de Educação. Parecer CNE/CEB no 18/2012, de 2/10/2012, 2012. Disponível em: http://portal. mec.gov.br $/$ index.php?option $=$ com_docman\&view $=$ download $\&$ alias $=11795$ pceb018-12\&category_slug=setembro-2012-pdf\&Itemid=30192. Acesso em: 29/10/17. 
. Lei no 11738, de 16 de julho de 2008. Regulamenta a alínea “e” do inciso III do caput do art. 60 do Ato das Disposições Constitucionais Transitórias, para instituir o piso salarial profissional nacional para os profissionais do magistério público da educação básica. Diário Oficial da União, Brasília, DF, 2008. Disponível em:www.planalto.gov.br/ccivil. Acesso em 4 mar. 2017.

. Lei no 9394, de 20 de dezembro de 1996. Estabelece as diretrizes e bases da educação nacional. Diário Oficial da União, DF, Brasília,1996. Disponível em: <www.mec.gov.br/legis/>. Acesso em: 20 out. 2006.

- Ministério da Administração Federal e Reforma do Estado. Câmara da Reforma do Estado. Plano diretor da reforma do aparelho do Estado, Brasília/ DF, 1995. Disponível em: <http://www.bresserpereira.org.br/documents/mare/ planodiretor $>$ Acesso em:4 mar. 2017.

Constituição da República Federativa do Brasil. Brasília: Senado Federal, 1988.

CASTELLS, M. A sociedade em rede. São Paulo: Paz e Terra, 1999.

DOURADO, L. F; OLIVEIRA, J. F. A qualidade da educação: perspectivas e desafios. Cad. Cedes. Campinas, vol. 29, n. 78, p. 201-215, maio/ago, 2009

FREITAS, C. C. S.; SILVA, M. S. P. O Plano de Desenvolvimento da Educação no contexto do novo desenvolvimentismo brasileiro. Revista brasileira de política e administração da educação, vol. 32, n 1, p. 69-88, jan./abril, 2016.

LIMA, L. A escola como organização educativa. $2^{a}$ ed. São Paulo: Cortez, 2003.

NOGUEIRA, M. A. Um estado para a sociedade civil: temas éticos e políticos da gestão democrática. $3^{\text {a }}$ ed. São Paulo: Cortez, 2011.

NÓVOA, A. Para uma análise das instituições escolares. In: NÓVOA, A. (Coord.). As organizações escolares em análise. $3^{\text {a }}$ ed. Lisboa: Publicações Dom Quixote, 1999, p. 13-42. 
OLIVEIRA, D. A. As políticas educacionais no governo Lula: rupturas e permanências. Revista brasileira de política e administração da educação. Porto Alegre, v. 25, n. 2, p. 197-210, maio/ago. 2009.

SANDER, Benno. Administração da Educação no Brasil: genealogia do conhecimento. Brasília. DF: Liber Livro, 2007.

SENNETT, R. A corrosão do caráter: consequências pessoais do trabalho no novo capitalismo, $3^{\mathrm{a}}$ ed. Trad. Marcos Santarrita. Rio de Janeiro/São Paulo: Editora Record, 1999.

CELSO LUIZ APARECIDO CONTI é doutor em educação, professor associado do Departamento de educação e do Programa de pós-graduação em educação da UFSCar. E-mail: celsocon@ufscar.br

EMÍLIA FREITAS DE LIMA é doutora em educação, professora sênior do Departamento de teorias e práticas pedagógicas e do Programa de pós-graduação em educação da UFSCar. E-mail: eflima281001@gmail.com

RENATA MARIA MOSCHEN NASCENTE é doutora em educação, professora adjunta do Departamento de educação e do Programa de pós-graduação em educação da UFSCar. E-mail: rmmnascente@gmail.com

Recebido em outubro de 2017 Aprovado em dezembro de 2017 